\title{
A RESPONSABILIDADE DO PROFISSIONAL NA DEFESA DO MEIO AMBIENTE ${ }^{1}$
}

http://dx.doi.org/10.21527/2176-6622.2018.50.27-37

Recebido em: $17 / 3 / 2018$

Aceito em: 20/6/2018

Thais Aldred lasbik

Graduação em Direito pela Faculdade Presidente Antônio Carlos de Ubá (2015). Habilitada pela Ordem dos Advogados do Brasil (2015). Mestre em Direito na Escola Superior Dom Helder Câmara. Integrante do Grupo de Pesquisa Tutela Penal do Meio Ambiente. aldrediasbik@yahoo.com.br

\section{Magno Federici Gomes}

Estágio Pós-doutoral em Direito Público e Educação pela Universidade Nova de Lisboa-Portugal (Bolsa Capes/BEX 3642/07-0). Estágios Pós-doutorais em Direito Civil e Processual Civil, Doutor em Direito e Mestre em Direito Processual, pela Universidad de Deusto-Espanha (Bolsa da Cátedra Unesco e do Gobierno Vasco-Espanha). Mestre em Educação pela PUC Minas. Professor do Doutorado e Mestrado Acadêmico em Direito Ambiental e Desenvolvimento Sustentável na Escola Superior Dom Helder Câmara. Professor Adjunto da PUC Minas e Professor Titular licenciado da Faculdade de Direito Arnaldo Janssen. Advogado Sócio do Escritório Moraes \& Federici Advocacia Associada. Líder do Grupo de Pesquisa: Regulação Ambiental da Atividade Econômica Sustentável (Rega)/CNPQ-BRA e integrante dos grupos: Centro de Investigação \& Desenvolvimento sobre Direito e Sociedade (Cedis)/FCT-PT, Núcleo de Estudos sobre Gestão de Políticas Públicas (Negesp)/ CNPQ-BRA e Metamorfose Jurídica/CNPQ-BRA. ORCID: <http://orcid.org/0000-0002-4711-5310?>. Currículo Lattes: <http://lattes.cnpq.br/1638327245727283>.federici@pucminas.br

\section{RESUMO}

A Política Nacional do Meio Ambiente (PNMA) estabelece, entre outros instrumentos, a Avaliação de Impactos Ambientais (AIA) e o Cadastro Técnico Federal de Atividades e Instrumentos de Defesa Ambiental (CTF/Aida), voltados para a promoção do desenvolvimento sustentável. A investigação pretendida neste artigo avalia os níveis da responsabilização administrativa dos profissionais envolvidos nessas atividades, questionando sua extensão, para apontar a incidência de penalidades administrativo-ambientais, além do regime ético-disciplinar estabelecido pelos respectivos conselhos de classe. 0 método utilizado foi o jurídico propositivo, além do hipotético dedutivo.

Palavras-chave: Cadastro Técnico Federal. Meio ambiente. Responsabilidade. Ético-disciplinar. Infração administrativa.

\section{THE RESPONSIBILITY OF THE PROFESSIONAL IN THE DEFENSE OF THE ENVIRONMENT}

\section{ABSTRACT}

The National Environmental Policy (PNMA) establishes, among other instruments, the Environmental Impact Assessment (AIA) and the Federal Technical Register of Activities and Instruments of Environmental Defense (CTF/Aida) aimed at promoting sustainable development. The research sought in this article assesses the levels of administrative accountability of professionals involved in these activities, questioning their extent, to indicate the incidence of administrative and environmental penalties, as well as the ethical disciplinary regime established by the respective class councils. The method used was the propositional legal in addition to the hypothetical deductive.

Keywords: Federal Technical Register. Environment. Responsibility. Ethical-disciplinary. Administrative infraction.

\section{SUMÁRIO}

1 Introdução. 2 Objetivos e Instrumentos da Política Nacional do Meio Ambiente. 3 Ética no Exercício Profissional e Responsabilidade Ambiental Juízo de Prelibação e de Delibação. 4 Atividades e Instrumentos de Defesa Ambiental e o Controle Exercido Pelos Órgãos Ambientais. 5 Considerações Finais. 6 Referências.

\footnotetext{
${ }^{1}$ Trabalho financiado pelo Projeto Fapemig no 5236-15, resultante dos Grupos de Pesquisas (CNPq): Regulação Ambiental da Atividade Econômica Sustentável (Rega), Negesp e Cedis (FCT-PT).
} 


\section{INTRODUÇÃO}

A realização de obras ou atividades modificadoras do ambiente estão sujeitas, por força de disposição constitucional, ao prévio estudo e avaliação de impacto ambiental, além do licenciamento promovido junto aos órgãos do Sistema Nacional do Meio Ambiente (Sisnama). A diretriz constitucional, portanto, e em que pesem os princípios da livre iniciativa e da ordem econômica, estabelece condições prévias para que possam se materializar. Os requisitos representam três instrumentos da Política Nacional do Meio Ambiente (PNMA), recepcionados da Lei Federal no 6.938/1981, sendo explícitos o licenciamento ambiental e a Avaliação de Impactos Ambientais (AIA), este contendo subentendida a figura das atividades e instrumentos de defesa ambiental.

Pretende-se, ao longo deste artigo, destacar dois dos instrumentos intrinsecamente relacionados, consubstanciados na AIA e nas atividades e instrumentos envolvidos na sua realização. O Cadastro Técnico Federal de Atividades e Instrumentos de Defesa Ambiental (CTF/Aida), nesse contexto, foi reconhecido pela PNMA como instrumento essencial à garantia dos objetivos nela estabelecidos. A opção contida na Lei 6.938/1981 evidencia a relevância da missão dada aos profissionais que fornecem subsídios essenciais à decisão das autoridades competentes em termos de regularização, controle e fiscalização ambiental no âmbito do Sisnama.

O CTF/Aida, desse modo, tem sua importância evidenciada pelo Conselho Nacional do Meio Ambiente (Conama), o qual impede a análise de estudos ambientais que instruem o licenciamento ambiental elaborados por profissionais irregulares em relação ao CTF/Aida. Diante, pois, do significado atribuído pelo ordenamento ambiental ao referido instrumento, este artigo visa à investigação sobre a responsabilidade por infração administrativa legalmente atribuída aos profissionais envolvidos na realização de estudos e monitoramento dos empreendimentos efetiva ou potencialmente causadores de degradação da qualidade ambiental, cujo problema reside na possibilidade de estender a aplicação das penalidades administrativo-ambientais, aplicáveis para os empreendedores, aos responsáveis técnicos, independentemente das sanções ético-disciplinares cabíveis por suas atividades profissionais.

Partindo, assim, da relevância legalmente reconhecida aos profissionais habilitados, a pesquisa levará em consideração o regime ético-disciplinar a que se subordinam os profissionais vinculados ao Conselho Federal de Engenharia e Agronomia (Confea), bem como ao Conselho Federal de Biologia (CFBIO), que congregam significativa parcela dos profissionais normalmente envolvidos na avaliação de impactos e elaboração de estudos ambientais para a instalação e operação de obras e atividades efetiva ou potencialmente causadoras de degradação. A abordagem, nesse sentido, considerará os elementos caracterizadores da conduta ética a ser identificada nas ações dos profissionais habilitados e vinculados aos conselhos de classe para atuação nos projetos de empreendimentos sujeitos ao controle ambiental dos órgãos do Sisnama.

O regime ético-disciplinar, todavia, pode não significar limite administrativo para aplicação de penalidades aos profissionais transgressores da ordem ambiental vigente. A finalidade do processo ético, nesse sentido, visa a resguardar a dignidade da profissão em detrimento de práticas antiéticas ou ilegais, mostrando-se relevante averiguar a responsabilidade em outras esferas legalmente estabelecidas.

Nesse cenário, o responsável técnico pela realização dos estudos ambientais, bem como pela AIA e fiscalização sobre a eficiência dos sistemas de controle existentes nas obras e atividades dos empreendimentos, deve ser submetido ao crivo do poder de polícia realizado pelos órgãos do Sisnama.

Foi adotado neste artigo o método jurídico propositivo, cujas fontes bibliográficas apresentam os seguintes temas: ética, meio ambiente e responsabilidade administrativa. Também foi empregado o método hipotético dedutivo, partindo-se do pressuposto de que todo aquele que, por ação ou omissão, concorre para a ocorrência do ilícito deve ser responsabilizado. O marco teórico do texto foi Hans Jonas (2006), que promove uma análise envolvendo ética e responsabilidade, constituindo esse o cerne da investigação que se promove neste texto.

Este trabalho foi subdividido em três partes, quais sejam: objetivos e instrumentos da PNMA, ética no exercício profissional e responsabilidade ambiental e atividades e instrumentos de defesa ambiental e o controle exercido pelos órgãos ambientais.

\section{OBJETIVOS E INSTRUMENTOS DA POLÍTICA NACIONAL DO MEIO AMBIENTE}

A instalação ou funcionamento de empreendimentos potencialmente causadores de significativa degradação do meio ambiente demandam a prévia realização de estudo sobre os impactos deles decorrentes, sendo incumbência do poder público exigi-lo, na forma da lei, com o fim de assegurar a efetividade do direito de 
todos ao meio ambiente ecologicamente equilibrado (BRASIL, 1988b). Nesse sentido, Bizawu e Gomes reconhecem "a necessidade de um novo paradigma que saiba conciliar o crescimento econômico e a conservação e proteção do meio ambiente para as gerações futuras", bem como a solidariedade humana para combater os riscos ao meio ambiente e promover o bem comum (2016, p. 23).

O comando constitucional, além de refletir os anseios evidenciados na literatura, a instituir um direito difuso, reflete o movimento já em curso no âmbito da PNMA, inaugurada pela Lei Federal no 6.938/1981. A referida política visa, em linhas gerais, à compatibilização do desenvolvimento econômico e social com a preservação do meio ambiente:

Art. 2ㅇ - A Política Nacional do Meio Ambiente tem por objetivo a preservação, melhoria e recuperação da qualidade ambiental propícia à vida, visando assegurar, no País, condições ao desenvolvimento socioeconômico, aos interesses da segurança nacional e à proteção da dignidade da vida humana, atendidos os seguintes princípios:

$[\ldots]$;

II - racionalização do uso do solo, do subsolo, da água e do ar;

III - planejamento e fiscalização do uso dos recursos ambientais;

IV - proteção dos ecossistemas, com a preservação de áreas representativas;

$\mathrm{V}$ - controle e zoneamento das atividades potencial ou efetivamente poluidoras;

$[\ldots]$

VII - acompanhamento do estado da qualidade ambiental;

VIII - recuperação de áreas degradadas;

IX - proteção de áreas ameaçadas de degradação;

[...]. (BRASIL, 1981).

Observa-se que alguns dos princípios norteadores dos objetivos da PNMA representam ações que deverão ser praticadas por todos, conforme evidenciado no artigo 225 da Constituição Federal da República do Brasil de 1988 (CR/88), na medida em que se impõe ao poder público e à coletividade o dever de defender o meio ambiente ecologicamente equilibrado e preservá-lo para as atuais e futuras gerações.

Ao estabelecer os objetivos da PNMA, a Lei Federal no 6.938/1981 definiu os instrumentos por meio dos quais seriam materializados. Entre os instrumentos da PNMA, para os fins almejados neste artigo, destacam-se a AIA e o CTF/Aida.

Os instrumentos legais de efetivação da AIA são os estudos de impacto ambiental e respectivos relatórios, promovidos por equipe técnica multidisciplinar habilitada, de composição variável de acordo com a complexidade dos impactos potenciais da obra ou atividade a ser desenvolvida pelo empreendimento. Os profissionais envolvidos na elaboração de estudos de impactos ambientais caracterizam-se, portanto, como instrumentos de defesa ambiental, sujeitos ao controle dos órgãos do Sistema Nacional do Meio Ambiente.

Observa-se, pois, que esses dois instrumentos da PNMA guardam entre si estreita relação, na medida em que os responsáveis técnicos pela realização de estudos ambientais e monitoramento dos sistemas de controle das fontes de poluição ou degradação ambiental dos empreendimentos são considerados mecanismos de defesa do meio ambiente.

O Instituto Brasileiro do Meio Ambiente e dos Recursos Naturais Renováveis - Ibama - é a instância competente pela gestão do CTF/Aida. No exercício dessa atribuição, portanto, editou a Instrução Normativa no 10, de 27 de maio de 2013, contendo o regramento do referido cadastro, dispondo de definições relevantes a ele relacionadas:

I - Cadastro Técnico Federal de Instrumentos e Atividades de Defesa Ambiental - CTF/AIDA: o cadastro que contém o registro das pessoas físicas e jurídicas que, em âmbito nacional, exerçam atividades nos termos dos Anexos I e ll;

$[\ldots]$ 


\section{Debate}

IX - responsável técnico: a pessoa física designada como responsável pelas atividades exercidas na forma dos Anexos I e II;

$X$ - responsabilidade técnica: responsabilidade pelo cumprimento de normas e padrões técnicos no desempenho de atividades declaradas junto ao CTF/Aida e sujeitas à fiscalização de Conselho de Fiscalização Profissional, por meio de documento de anotação de responsabilidade técnica;

[...] (BRASIL, 2013).

As atividades mencionadas nos anexos I e II da IN Ibama 10/2013 correspondem ao exercício profissional vinculado a atividades relacionadas ao controle das fontes de poluição ou degradação ambiental. Não obstante, em que pese a relação existente com o exercício profissional, o CTF /Aida não substitui os conselhos de classe no controle sobre a regularidade das profissões. O exercício profissional, nos termos dos artigos 50, XIII, e 21, XXIV, da CR/88, é fiscalizado pelos respectivos conselhos de classe, criados por leis específicas. Esse controle é denominado por Aragão como "regulação pública não estatal", pela qual "as entidades sociais [...], assumem, no seu âmbito, a função de regulação, sem que, contudo, sejam transformadas em órgãos do Estado, que, todavia, Ihes empresta a sua autoridade por via legislativa ou constitucional" (ARAGÃO, 2013, p. 32).

De outro modo, o CTF Aida visa ao controle sobre as pessoas físicas e jurídicas que, profissionalmente, executam ações relacionadas à gestão ambiental, sendo vedada aos órgãos do Sistema Nacional do Meio Ambiente - Sisnama - a análise de projetos e estudos, no âmbito do licenciamento ambiental, de pessoas físicas ou jurídicas que não estejam devidamente inscritas e regulares no Cadastro Técnico Federal:

Art. 2ㅇ A Secretaria Especial do Meio Ambiente - Sema² e os órgãos ambientais, no prazo de 90 dias, a partir da publicação desta Resolução, somente aceitarão, para fins de análise, projetos técnicos de controle da poluição ou estudos de impacto ambiental, cujos elaboradores sejam profissionais, empresas ou sociedades civis regularmente registradas no Cadastro que trata o art. 1‥

É certo, todavia, que tanto o controle promovido pelo Ibama quanto aquele efetuado pelos conselhos profissionais de classe correspondem ao exercício do poder de polícia, definido pelo artigo 78 do Código Tributário Nacional (CTN):

Considera-se poder de polícia atividade da administração pública que, limitando ou disciplinando direito, interesse ou liberdade, regula a prática de ato ou abstenção de fato, em razão de interesse público concernente à segurança, à higiene, à ordem, aos costumes, à disciplina da produção e do mercado, ao exercício de atividades econômicas dependentes de concessão ou autorização do poder público, à tranqüilidade pública ou ao respeito à propriedade e aos direitos individuais ou coletivos (BRASIL, 1966).

A clássica definição dada ao instituto é objeto de crítica promovida por Aragão (2013, p. 34), em virtude da atribuição ao poder público da competência para dobrar os direitos individuais ao interesse coletivo indefinido. Gomes e Ferreira, nesse contexto, apontam que a boa administração pública é pressuposto da sustentabilidade, ecoando "no sentido de mobilizar todas as atividades ao filtro dos princípios da prevenção e precaução, num exercício contínuo de previsibilidade de acidentes que possam vir a ser catastróficos do ponto de vista ambiental" (GOMES; FERREIRA, 2017, p. 104).

Aragão, em que pese a crítica, argumente que o poder de polícia deve ser adequado à complexidade socioeconômica e "que seja funcionalizado em razão dos interesses públicos a serem atendidos pelas atividades privadas, em relação às quais o poder público pode, observados os limites legais, dimensionar de maneira dinâmica o conteúdo e a extensão" (ARAGÃO, 2013, p. 34).

O CTF/Aida, nesse aspecto, representa o controle pelos órgãos do Sisnama do exercício profissional naquilo que afeta a viabilidade e desempenho ambiental dos empreendimentos efetiva ou potencialmente modificadores do meio ambiente. A relevância do exercício profissional nessa matéria decorre dos múltiplos fatores relacionados à gestão dos recursos naturais.

\footnotetext{
${ }^{2}$ A Secretaria Especial do Meio Ambiente - Sema, vinculada ao Ministério do Interior, foi extinta pela Lei no 7.735, de 22 de fevereiro de 1989, que criou o Instituto Brasileiro do Meio Ambiente e dos Recursos Naturais Renováveis - Ibama. As atribuições em matéria ambiental são atualmente do Ministério do Meio Ambiente (BRASIL, 1988a).
} 
Os "estudos necessários ao processo de licenciamento deverão ser realizados por profissionais legalmente habilitados, às expensas do empreendedor", nos termos da Resolução Conama no 237, de 19 de dezembro de 1997. Esse comando normativo evidencia que o potencial poluidor é que deve arcar com as despesas decorrentes dos estudos ambientais para a instalação e funcionamento do seu empreendimento. A regra, pois, materializa, em alguma medida, o princípio do poluidor-pagador, no sentido de incorporar no custo do seu empreendimento os valores despendidos em todas as etapas do empreendimento, inclusive de planejamento.

O exercício profissional envolvido na elaboração de estudos, bem como no monitoramento e controle das fontes de degradação ambiental, além de assegurar a observância dos parâmetros legalmente estabelecidos para a execução de obras ou operação de atividades efetiva ou potencialmente poluidoras, viabiliza a descoberta ou aprimoramento das técnicas de uso dos recursos naturais, de modo a torná-lo mais eficiente. A eficiência, neste aspecto, corresponde a resultados mais expressivos sob a ótica econômica e social, no mesmo passo em que se reduzem os custos ou danos ambientais na execução de obras ou funcionamento das atividades.

Assim, identificada a ação dos profissionais na avaliação de impactos ambientais, ambas figuras previstas no ordenamento jurídico brasileiro como instrumentos da PNMA, abre-se espaço para ampliar a discussão sobre a relevância desses profissionais e suas responsabilidades para a promoção do desenvolvimento sustentável. Esta abordagem compõe a matéria do tópico subsequente.

\section{3 ÉTICA NO EXERCÍCIO PROFISSIONAL E RESPONSABILIDADE AMBIENTAL}

Conforme abordagem promovida no tópico anterior, o desenvolvimento das atividades por profissionais legalmente habilitados para análise de impactos ambientais, assume elevada relevância, por fornecer aos órgãos ambientais competentes subsídios para cumprimento de suas missões institucionais. Os órgãos ambientais, conquanto disponham de informações gerais existentes nos inventários e zoneamentos disponíveis, ou informações acumuladas nos bancos de dados dos seus sistemas, estes são pouco precisos e, geralmente, desatualizados. Assim, os órgãos e instituições integrantes do Sisnama dependem de dados primários para conhecimento sobre as reais circunstâncias e impactos potenciais decorrentes da pretensa instalação e funcionamento dos empreendimentos.

A regularização e o controle sobre as fontes de poluição ou degradação, promovidos pela administração pública no exercício do poder de polícia sobre os empreendimentos, dependem das informações técnicas e jurídicas prestadas pelos profissionais que se dedicam ao mercado da assessoria ambiental. Nesse contexto, o exercício das atividades privadas no âmbito da avaliação de impactos ambientais impõe ao profissional elevada responsabilidade, que acumula deveres éticos com os princípios da administração pública e defesa do meio ambiente ecologicamente equilibrado.

Em termos éticos, convém para os fins pretendidos neste artigo destacar as definições dadas por alguns dos principais conselhos de classe quanto à qualidade das informações prestadas por seus congregados. Nesse sentido, o Confea editou a Resolução no 1.002, de 29 de novembro de 2002, que vincula o ser ético à qualidade e honestidade no exercício profissional. A preocupação dos conselhos de classe, assim, atende ao anseio que Kalil e Ferreira revelam existir no ordenamento constitucional vigente:

A complexidade dos problemas ambientais enfrentados na modernidade e as novas reivindicações das sociedades na conjugação dos direitos de primeira, segunda e terceira dimensões, ${ }^{3}$ particularmente pela ênfase conferida à proteção do "macrobem ambiental," ${ }^{4}$ tem sido um dos importantes vetores de mudanças comportamentais que fizeram florescer uma preocupação ética e socioambientalmente responsável, o que tem ensejado a configuração de um novo modelo de Estado condizente com essa preocupação (KALIL; FERREIRA, 2017, p. 342).

\footnotetext{
${ }^{3}$ Considerando, ainda, aqueles tidos de quarta e quinta dimensões, ainda que não reconhecidos institucionalmente.

${ }^{4}$ Morato Leite destaca que a legislação pátria conferiu ao meio ambiente a conotação de macrobem por ter adotado uma visão globalizada e integral, caracterizando-o, portanto, como amplo, de natureza imaterial, indivisível e difuso, não obstante também existir o microbem, entendido como todos os bens que compõem o meio ambiente.
} 
O Código de Ética do Confea contempla, a propósito da matéria ambiental, que a ação dos profissionais se volte "para o bem-estar e o desenvolvimento do homem, em seu ambiente e em suas diversas dimensões: como indivíduo, família, comunidade, sociedade, nação e humanidade; nas suas raízes históricas, nas gerações atual e futura" (CONSELHO FEDERAL DE ENGENHARIA E AGRONOMIA, 2002). A preocupação evidenciada pelo conselho de classe, nesses termos, aproxima-se do ideal do direito humano, na abordagem promovida por Jonas, no dever de existir e do modo de existir da posteridade:

É um dever desse tipo que se trata, no caso, da responsabilidade em relação à humanidade futura. Em primeiro lugar, isso significa um dever para com a existência da humanidade futura, independentemente do fato de que nossos descendentes diretos estejam entre ela; em segundo lugar, um dever em relação ao seu modo de ser, à sua condição. O primeiro dever inclui o dever de reprodução (ainda que não necessariamente para cada indivíduo particular), e, assim como esta última, esse dever não pode ser deduzido como uma extensão do dever do autor em relação à existência da qual ele é a causa: se esse dever existe, como gostaríamos de supor, ele ainda não foi fundamentado (JONAS, 2006, p. 90-91).

Esse objetivo, portanto, encontra íntima relação com os fundamentos constitucionais de defesa do meio ambiente ecologicamente equilibrado, abrangendo suas múltiplas definições, e incluindo a igualdade de oportunidades entre as gerações humanas. Ao seguir na abordagem que se faz quanto aos fundamentos da ação ética, o Confea aponta princípios que devem nortear as ações do profissional:

I) A profissão é bem social da humanidade e o profissional é o agente capaz de exercê-la, tendo como objetivos maiores a preservação e o desenvolvimento harmônico do ser humano, de seu ambiente e de seus valores;

II) A profissão é bem cultural da humanidade construído permanentemente pelos conhecimentos técnicos e científicos e pela criação artística, manifestando-se pela prática tecnológica, colocado a serviço da melhoria da qualidade de vida do homem;

[...];

IV) A profissão realiza-se pelo cumprimento responsável e competente dos compromissos profissionais, munindo-se de técnicas adequadas, assegurando os resultados propostos e a qualidade satisfatória nos serviços e produtos e observando a segurança nos seus procedimentos;

V) A profissão é praticada através do relacionamento honesto, justo e com espírito progressista dos profissionais para com os gestores, ordenadores, destinatários, beneficiários e colaboradores de seus serviços, com igualdade de tratamento entre os profissionais e com lealdade na competição;

VI) A profissão é exercida com base nos preceitos do desenvolvimento sustentável na intervenção sobre os ambientes natural e construído, e na incolumidade das pessoas, de seus bens e de seus valores;

\section{[...] (CONSELHO FEDERAL DE ENGENHARIA E AGRONOMIA, 2002).}

Os princípios éticos norteadores da conduta dos profissionais vinculados ao Confea evidenciam a relevância de suas atividades para a plena realização dos anseios humanos, incluindo a preservação ambiental e o desenvolvimento sustentável.

Essa guia de ação adotada no âmbito do Confea também encontra amparo no Código de Ética Profissional do Biólogo, estabelecido pela Resolução no 2, de 5 de março de 2002, segundo o qual a atividade desse profissional "deverá sempre consagrar respeito à vida, em todas as suas formas e manifestações e à qualidade do meio ambiente" (CONSELHO FEDERAL DE BIOLOGIA, 2002). Nesse sentido, ainda, a referida Resolução estabelece obrigações ao biólogo, assegurando os propósitos éticos eleitos pelo conselho de classe para atuação desses profissionais:

Art. 6 - São deveres profissionais do biólogo:

$[\ldots]$

VII - Não ser conivente com os empreendimentos ou atividades que possam levar a riscos, efetivos ou potenciais, de prejuízos sociais, de danos à saúde ou ao meio ambiente, denunciando o fato, formalmente, mediante representação ao CRBio de sua região e/ou aos órgãos competentes, com discrição e fundamentação;

$[\ldots]$ 
Art. 17 - O biólogo deverá efetuar a avaliação e denunciar situações danosas ou potencialmente danosas decorrentes da introdução ou retirada de espécies em ambientes naturais ou manejados.

$[\ldots]$

Art. 19 - O biólogo deve ter pleno conhecimento da amplitude dos riscos potenciais que suas atividades poderão exercer sobre os seres vivos e meio ambiente, procurando e implementando formas de reduzi-los e eliminá-los, bem como propiciar procedimentos profiláticos eficientes a serem utilizados nos danos imprevistos.

Art. $20-[\ldots]$.

Parágrafo único: Não será observado o sigilo profissional previsto no caput deste artigo, quando os resultados indicarem riscos ou prejuízos à saúde humana, à biodiversidade e ao meio ambiente, devendo o profissional comunicar os resultados às autoridades competentes (CONSELHO FEDERAL DE BIOLOGIA, 2002).

As diretrizes éticas para o exercício profissional do biólogo, portanto, guiam-se pela intolerância às práticas contrárias às regras de proteção ambiental, impondo-se ao profissional, além da vedação à conivência, o dever de comunicar às autoridades ambientais toda ação potencialmente causadora de dano sobre o meio ambiente.

Para os propósitos almejados neste artigo, limita-se aos dispositivos éticos anteriormente abordados, que abrangem significativa parcela dos profissionais envolvidos na avaliação de impactos ambientais, bem como na gestão e monitoramento dos sistemas de controle ambiental mantidos pelos empreendimentos que operam como fontes de poluição ou degradação ambiental. Os conselhos de classe, portanto, impõem aos profissionais que suas ações ocorram de acordo com as disposições legais vigentes, e em conformidade com os princípios norteadores do Direito Ambiental e do desenvolvimento sustentável.

Conhecida a premissa ambiental que emana do regramento ético dos conselhos profissionais, cabe aprofundar na matéria para entender a forma pela qual os órgãos do Sisnama fazem cumprir os propósitos do controle sobre essas atividades na relação com as fontes de poluição ou degradação da qualidade ambiental. Esse propósito compõe a abordagem que se segue no item subsequente, com lastro na legislação estabelecida pelo Conama.

\section{ATIVIDADES E INSTRUMENTOS DE DEFESA AMBIENTAL E O CONTROLE EXERCIDO PELOS ÓRGÃOS AMBIENTAIS}

Conforme exposição promovida nos itens anteriores, o desenvolvimento de ações profissionais na avaliação de impactos ambientais de empreendimentos potencialmente causadores de danos sobre o meio ambiente é objeto de controle ético pelos respectivos conselhos de classe. Também foi ventilado que essas atividades são contempladas no âmbito da PNMA como instrumentos de defesa do meio ambiente.

Em relação aos preceitos definidos pelos conselhos de classe, o descumprimento, por certo, implica a instauração de processo ético-disciplinar, para aplicação de sanções variáveis de acordo com a gravidade da transgressão perpetrada. Noutro giro, a título de controle sobre os reflexos ambientais dessas ações, o Conama assim estabelece:

Art. 11 - Os estudos necessários ao processo de licenciamento deverão ser realizados por profissionais legalmente habilitados, às expensas do empreendedor.

Parágrafo único - O empreendedor e os profissionais que subscrevem os estudos previstos no caput deste artigo serão responsáveis pelas informações apresentadas, sujeitando-se às sanções administrativas, civis e penais (BRASIL, 1997).

A disposição normativa estabelecida pelo Conama demanda habilitação técnica dos profissionais envolvidos na elaboração dos estudos ambientais, de acordo com a natureza e complexidade das obras ou atividades, e das características locacionais do empreendimento pretendido no âmbito do licenciamento ambiental. A habilitação técnica, por sua vez e nos termos do artigo 5으 XIII, da CR/88, pressupõe o atendimento de qualificação estabelecida pela legislação específica, cabendo aos respectivos conselhos de classe o exercício do controle sobre a adequação dos profissionais a ele vinculados. 
Além da habilitação técnica definida em lei, o dispositivo contido na norma do Conama prevê que tanto o empreendedor quanto os profissionais que subscrevem os estudos ambientais que instruem o processo de licenciamento ambiental são responsáveis pelas informações neles prestadas, podendo ser penalizados nas três esferas de responsabilização previstas no ordenamento vigente.

O duplo controle exercido sobre a atividade profissional (ético-profissional e administrativo) observa o preceito da proporcionalidade, envolvendo a tutela do meio ambiente ecologicamente equilibrado e o exercício profissional. Nesse sentido, Ávila (2016, p. 191) aborda a questão partindo da ótica de vedação do excesso, levando-se em consideração os aspectos da necessidade, adequação e proporcionalidade em sentido estrito. Sob essa lógica, observa-se que o nível de responsabilidade envolvendo o profissional Aida é compatível com a relevância do interesse tutelado, sem comprometer o desenvolvimento do ofício dentro das prerrogativas asseguradas pelos respectivos conselhos de classe. Assim:

O exame de proporcionalidade aplica-se sempre que houver uma medida concreta destinada a realizar uma finalidade. Nesse caso devem ser analisadas as possibilidades de a medida levar à realização da finalidade (exame da adequação), de a medida ser a menos restritiva aos direitos envolvidos dentre aquelas que poderiam ter sido utilizadas para atingir a finalidade (exame da necessidade) e de a finalidade pública ser tão valorosa que justifique tamanha restrição (exame da proporcionalidade em sentido estrito) (ÁVILA, 2016, p. 206).

Sob essa ótica, pois, proporcional é a regra contida no artigo 3으, IV, da Lei Federal no 6.938/1981, segundo a qual poluidor é aquele que, direta ou indiretamente, ocasiona degradação ambiental. Nesse sentido, a depender da informação omitida ou incompatível, que resulte em danos ambientais ou tenha potencial de ocasioná-los, os profissionais que a prestam devem ser responsabilizados.

A lógica geral acerca da responsabilidade, nesse aspecto, é retratada de maneira didática por Jonas (2006, p. 165), para quem o domínio sobre a causa é pressuposto para a responsabilidade. Dessa forma, assevera o autor, o agente é responsável pelas consequências dos seus atos, independentemente da intenção quanto ao resultado, devendo «os danos causados serem reparados, ainda que a causa não tenha sido um ato mau e suas conseqüências não tenham sido nem previstas nem desejadas" (JONAS, 2006, p. 165).

A Advocacia Geral do Estado (AGE) de Minas Gerais, nesse sentido, firmou entendimento vinculante à Administração Ambiental estadual segundo o qual se aplica a responsabilidade concorrente de todo aquele que, por ação ou omissão, concorra para a prática da infração (MINAS GERAIS, 2017). Dessa forma, os dados fornecidos pelo empreendedor no seio de um estudo ambiental, ou omissão acerca de inadequações existentes na área do empreendimento, ensejam a penalização dos profissionais envolvidos, tanto quanto cabível aos responsáveis legais pela obra ou atividade.

O posicionamento sustentado pela AGE é reflexo da legislação estadual, e encontra-se condensada no recente regulamento estabelecido pelo Decreto Estadual $n=47.383 / 2018$, em cujo artigo 112 , $\S 1$, determina a responsabilização de todo aquele que pratique a infração, abrangendo os autores diretos, contratuais, bem como todo aquele que concorra para a prática ilícita ou dela obtenha vantagem. A concorrência é preceito geral da responsabilidade, podendo atingir até mesmo o usuário do serviço prestado pelo infrator, na hipótese em que sua ação contribua para o resultado danoso (BORGES; ZIESEMER, 2015, p. 110).

A opção da norma, nesse aspecto, satisfaz ao preceito da razoabilidade, na medida em que define a responsabilidade concorrente daquele que, de algum modo, contribui para a ocorrência da infração. Para Ávila (2016, p. 196), a razoabilidade implica a preservação de princípios de valores igualmente relevantes, e que "interpretação diversa das circunstâncias de fato levaria à restrição de algum princípio constitucional, como o princípio do devido processo legal, nos casos analisados."

O profissional, nesse aspecto, que executa atividades de defesa do meio ambiente, no cumprimento do propósito estabelecido pela legislação vigente e de acordo com as melhores técnicas disponíveis no mercado, o faz constrangido sob os mesmos princípios e normas regentes da administração pública ambiental. Nesse aspecto, a responsabilização ambiental incide sobre aquele que contribui ou promove, no exercício profissional, ações lesivas ao meio ambiente ou à fé pública na gestão dos recursos ambientais. Com efeito, inobstante existirem dispositivos ético-disciplinares norteadores da conduta profissional, observa-se, por vezes, o cabimento de sanções em níveis complementares, como forma de assegurar a efetiva satisfação dos valores defendidos pela sociedade (RIBEIRO; SENESI FILHO, 2014, p. 309). 
Não se trata, nesse caso, de usurpação, pelos órgãos do Sisnama, da competência disciplinar na aplicação de penalidades aos profissionais vinculados aos respectivos conselhos de classe. Acerca dessa discussão, Naves e Reis (2016) tecem considerações sobre as múltiplas espécies da responsabilidade administrativa:

[...], a responsabilidade administrativa é atinente ao ilícito administrativo, isto é, a condutas que ofendam a regulação da administração pública em todas as suas esferas e âmbitos. Pode, portanto, ser uma medida sancionatória aplicada àquele que está nos quadros da administração pública, bem como aquele que exerce uma atividade que está sob a fiscalização, autorização, permissão ou concessão do poder público. Por isso, mesmo particulares podem ser responsabilizados administrativamente em razão da atividade em questão estar dentro da seara regulatória da administração pública.

A responsabilização profissional [...] por seu órgão de classe é uma responsabilidade administrativa [...]. Também a imposição de multas por degradação ambiental é uma forma de responsabilização administrativa; [...] (NAVES; REIS, 2016, p. 194-195).

A infração perpetrada, nesse caso, pode ocasionar a responsabilização administrativa em níveis distintos, sendo um ético-disciplinar, apurado em processo específico diante da autoridade competente pelo controle das atividades profissionais, e outro por infração administrativa à legislação ambiental vigente, e processada pelos órgãos ambientais integrantes do Sisnama.

No âmbito da infração administrativa, pois, o profissional pode responder de forma concorrente com o empreendedor, com a penalidade sendo aplicada de acordo com a relevância da sua participação, guardada a proporção decorrente do seu porte em relação ao empreendimento atendido por seus serviços. A responsabilidade, assim, para Naves e Reis (2016), "é uma medida sancionatória que se aplica aos impactos negativos de uma conduta, seja dano propriamente dito, seja a criação de perigos" (p. 191). Nesse sentido, a responsabilidade por infração administrativa surge para o profissional conjuntamente com o empreendedor na medida em que contribuiu para a ocorrência do dano ou perigo de dano.

O empreendedor, por certo, almeja sempre a alternativa mais vantajosa para o seu empreendimento, tanto pelo local quanto pelos custos de execução e manutenção. O profissional contratado, todavia, deve resistir ao assédio promovido, pelo empreendedor, para recomendar as alternativas menos impactantes sobre o meio ambiente, associadas à técnica mais eficiente em termos de controle sobre as fontes de poluição ou degradação ambiental. Esse, a propósito, é o norte indicado pelo Conama, segundo o qual a avaliação de impacto deve ser promovida por profissional independente em relação ao empreendedor, para o íntegro exercício do seu ofício. Nesse sentido, "o estudo de impacto ambiental será realizado por equipe multidisciplinar habilitada, não dependente direta ou indiretamente do proponente do projeto e que será responsável tecnicamente pelos resultados apresentados" (BRASIL, 1986).

Nesse cenário, portanto, em que tanto o contratante quanto o contratado compartilham o dever de observar as regras e restrições impostas pela legislação ambiental vigente, a responsabilização administrativa, civil e criminal será compartilhada entre empreendedor e profissionais que o assessoraram. Essa abordagem, a propósito do zelo esperado do profissional, repercute naquilo que Jonas identifica como atitude irresponsável:

O jogador que arrisca no cassino todo o seu patrimônio age de forma imprudente; quando se trata não do seu patrimônio, mas do de outro, age de forma criminosa; quando é pai de família, sua ação é irresponsável, mesmo que se trate de bens próprios e independentemente do fato de ganhar ou perder. $\mathrm{O}$ exemplo nos mostra que só pode agir irresponsavelmente quem assume responsabilidades. A responsabilidade rejeitada nesse exemplo é do tipo mais abrangente e duradouro (JONAS, 2006, p. 168).

Nesse aspecto, a penalização ao responsável técnico por infração administrativa assume caráter pedagógico, para constrangê-lo à prestação honesta dos seus serviços quando da elaboração dos estudos ambientais, bem como das orientações e monitoramento sobre a eficiência dos seus sistemas de controle das fontes poluidoras.

A previsão normativa do Conama é compatível com a importância conferida ao exercício profissional nesse aspecto no âmbito da respectiva política nacional, que o eleva à categoria de instrumento de defesa do meio ambiente. Nesse sentido, as ações definidas pelos conselhos de classe aos quais se encontram vincula- 
dos os profissionais do serviço ambiental, associadas às cominações legalmente previstas aos transgressores das normas de proteção ambiental, consubstanciam-se em formas eficientes para garantir a segura prestação de serviços aos empreendimentos potencialmente causadores de degradação ao meio ambiente.

\section{CONSIDERAÇÕES FINAIS}

A CR/88 estabelece que a realização de obras ou atividades potencialmente poluidoras, além do licenciamento ambiental, dependerão de Estudo Prévio de Impacto Ambiental (Epia). A diretriz constitucional relacionada a condições prévias para execução de ações inseridas no âmbito da livre iniciativa encerra dois instrumentos da PNMA, sendo explícitos o licenciamento ambiental e a AIA, este contendo subentendida a figura das atividades e instrumentos de defesa ambiental.

A abordagem contida neste artigo orbita os dois instrumentos correlatos, consubstanciados na AlA e nas atividades e instrumentos envolvidos na sua realização. O CTF/Aida, nesse sentido, é reconhecido no seio da PNMA como um de seus instrumentos. A opção legislativa, por certo, decorre do controle promovido sobre aqueles que executam a relevante missão de apresentar ao Sisnama as informações essenciais à decisão das autoridades competentes em termos de regularização, controle e fiscalização ambiental.

A relevância do CTF/Aida, desse modo, é evidenciada pelo Conama, cuja Resolução no 1/1989 condicionou a análise de qualquer estudo ambiental à apresentação do comprovante de regularidade junto ao CTF/ Aida.

A investigação trilhou por algumas disposições regulamentares sobre o regime ético dos profissionais vinculados ao Confea, bem como ao CFBIO, que congregam significativa parcela dos profissionais normalmente envolvidos na AIA e elaboração de estudos ambientais para a instalação e operação de obras e atividades efetiva ou potencialmente causadoras de degradação.

A abordagem, nesse sentido, apontou que a honestidade e a melhor técnica norteiam as ações dos profissionais habilitados e vinculados aos conselhos de classe para atuação nos projetos de empreendimentos sujeitos ao controle ambiental dos órgãos do Sisnama. Nesse domínio, os profissionais encontram-se constrangidos pelo regime ético-disciplinar, sujeitos a sanções legalmente estabelecidas em casos de inobservância das regras definidas pelos respectivos conselhos de classe.

Observou-se, outrossim, que o regime ético-disciplinar não se apresenta como exclusivo limite administrativo para aplicação de penalidades aos profissionais transgressores da ordem ambiental vigente. A finalidade do processo ético, nessa perspectiva, visa a resguardar a dignidade do conjunto dos profissionais identificados por determinado conselho de classe.

Nesse cenário, o responsável técnico pela realização dos estudos ambientais e pela AIA e fiscalização sobre a eficiência dos sistemas de controle existentes nas obras e atividades dos empreendimentos, deve ser submetido ao crivo do poder de polícia realizado pelos órgãos do Sisnama. O CNMA, nesse sentido, previu por meio da Resolução no 237/1997 que a responsabilidade pelas informações prestadas nos estudos ambientais recai tanto no empreendedor quanto nos profissionais que os subscrevem.

Nessa medida, a aplicação de penalidades ético-disciplinares pelos conselhos de classe aos profissionais transgressores das regras próprias de conduta é cumulável com as sanções definidas para infrações administrativas perpetradas no contexto de uma avaliação de impactos, ou na inadequada gestão dos sistemas de controle cabíveis para o empreendimento, de acordo com o local e características de instalação ou funcionamento. Dessa forma, a imposição de penalidades pelos órgãos e instituições do Sisnama, de forma concorrente, seguirá o princípio da proporcionalidade, que ensejará penalidade mais gravosa a quem detém, de fato, o domínio sobre a execução das atividades do empreendimento, não se eximindo da responsabilidade o responsável técnico contratado.

A responsabilidade administrativa ambiental entre empreendedor e certificador, nesse aspecto, é concorrente, na medida da relevância de sua ação ou omissão para a prática infracional, prevista na legislação ambiental vigente. 


\section{REFERÊNCIAS}

ARAGÃO, Alexandre Santos de. Agências reguladoras e a evolução do direito administrativo econômico. 3. ed. rev. e atual. Rio de Janeiro: Forense, 2013.

ÁVILA, Humberto. Teoria dos princípios: da definição à aplicação dos princípios jurídicos. 17. ed. rev. e atual. São Paulo: Malheiros, 2016.

BRASIL. Conselho Nacional do Meio Ambiente. Resolução no 1, de 23 jan. 1986. Dispõe sobre critérios básicos e diretrizes gerais para o Relatório de Impacto Ambiental-Rima. Diário Oficial da União, Brasília, 17 fev. 1986, seção 1, p. 2.548-2.549. Disponível em: <http://www.mma.gov.br/port/conama/res/res86/res0186.html>. Acesso em: 23 dez. 2017.

. Conselho Nacional do Meio Ambiente. Resolução no 1, de 13 jun. 1988. Dispõe sobre o Cadastro Técnico Federal de atividades e instrumentos de defesa ambiental. Diário Oficial da União, Brasília, 15 jun. 1988a, p. 10.845. Disponível em: <http://www.mma.gov.br/port/conama/legiabre.cfm?codlegi=65>. Acesso em: 23 dez. 2017.

. Conselho Nacional do Meio Ambiente. Resolução no 237, de 19 dez. 1997. Dispõe sobre a revisão e complementação dos procedimentos e critérios utilizados para o licenciamento ambiental. Diário Oficial da União, Brasília, 22 dez. 1997, p. 30.841-30.843. Disponível em: <http://www.mma.gov.br/port/conama/res/res97/res23797.html>. Acesso em: 23 dez. 2017.

Constituição da República Federativa do Brasil de 1988. Diário Oficial da União, Brasília, out. 1988b. Disponível em <http://www.planalto.gov.br/ccivil_03/constituicao/constituicaocompilado.htm>. Acesso em: 23 dez. 2017.

. Lei no 5.172, de 25 de out. de 1966. Dispõe sobre o Sistema Tributário Nacional e institui normas gerais de direito tributário aplicáveis à União, Estados e Municípios. Diário Oficial da União, Brasília, out. 1966. Disponível em: <http://www. planalto.gov.br/ccivil_03/leis/l5172.htm>. Acesso em: 5 dez. 2017.

. Lei no 6.938, de 31 de ago. de 1981. Dispõe sobre a Política Nacional do Meio Ambiente, seus fins e mecanismos de formulação e aplicação, e dá outras providências. Diário Oficial, Brasília, ago. 1981. Disponível em: <http://www.planalto.gov. br/ccivil_03/leis/L6938.htm>. Acesso em: 23 dez. 2017.

. IBAMA. Instrução Normativa no 10, de 27 maio 2013. Diário Oficial da União, Brasília, 28 maio 2013, seção 01 , p. 62. Disponível em: <http://www.icmbio.gov.br/cepsul/images/stories/legislacao/Instrucao_normativa/2013/in_ibama_10_2013_ regulamentar_cadastrot\%C3\%A9cnicofederal_atividades_instrumentos_defesaambiental_ctf_aida.pdf $>$. Acesso em: 4 fev. 2019.

BIZAWU, Kiwonghi; GOMES, Magno Federici. Oil exploitation at Virunga park as a threat to the environment and to endangered animal species. Veredas do Direito, Belo Horizonte, v. 13, n. 27, p. 11-29, set./dez. 2016. Disponível em: <http://www. domhelder.edu.br/revista/index.php/veredas/article/view/897>. Acesso em: 24 jan. 2018.

BORGES, Luiz Fernando Rossetti; ZIESEMER, Henrique da Rosa. A responsabilidade civil objetiva do município na regularização de loteamentos clandestinos e irregulares. Revista Direito em Debate, v. 24, n. 44, p. 93-113, jul. 2015. Disponível em: <https:// www.revistas.unijui.edu.br/index.php/revistadireitoemdebate/article/view/4408>. Acesso em: 15 mar. 2018.

CONSELHO FEDERAL DE BIOLOGIA. Resolução no 2, de 5 de mar. de 2002. Aprova o Código de Ética do Profissional Biólogo. Diário Oficial da União, Brasília, mar. 2002. Disponível em: <http://www.cfbio.gov.br/artigos/RESOLUcaO-N\%C2\%BA-2-DE-5-DE-MARcO-DE-2002 >. Acesso em: 23 dez. 2017.

CONSELHO FEDERAL DE ENGENHARIA E AGRONOMIA (Confea). Resolução no 1.002, de 26 de nov. de 2002. Adota o Código de Ética Profissional da Engenharia, da Agronomia, da Geologia, da Geografia e da Meteorologia e dá outras providências. Diário Oficial da União, Brasília, nov. 2002. Disponível em: <http://www.confea.org.br/media/codigo_etica_sistemaconfea_8edicao_2015.pdf>. Acesso em: 23 dez. 2017.

GOMES, Magno Federici; FERREIRA, Leandro José. A dimensão jurídico-política da sustentabilidade e o direito fundamental à razoável duração do procedimento. Revista do Direito, Santa Cruz do Sul, n. 52, v. 2, p. 93-111, maio/set. 2017. Disponível em: <http://dx.doi.org/10.17058/rdunisc.v2i52.8864>. Acesso em: 22 fev. 2018.

JONAS, Hans. O princípio da responsabilidade: ensaio de uma ética para a civilização tecnológica. Tradução Marijane Lisboa e Luiz Barros Montez. Rio de Janeiro: Contraponto: Ed. PUC-Rio, 2006.

KALIL, Ana Paula Maciel Costa; FERREIRA, Heline Sivini. A dimensão socioambiental do Estado brasileiro. Veredas do Direito, Belo Horizonte, v. 14, n. 28, p. 329-359, jun. 2017. Disponível em: <http://www.domhelder.edu.br/revista/index.php/veredas/ article/view/1010/591>. Acesso em: 29 dez. 2017.

MINAS GERAIS. Advocacia Geral do Estado (AGE). Direito Administrativo sancionador. Meio ambiente. Tríplice responsabilidade. Art. 225, § 3의 da CR/88. Responsabilidade administrativa ambiental. Natureza Subjetiva. Culpabilidade. Intranscendência das sanções administrativas. Jus puniendi. Devido processo substancial. Culpa presumida. Parecer Jurídico $n$ o 15.877 , de 23 de maio de 2017. Procuradora do Estado: Nilza Aparecida Ramos Nogueira. Disponível em: <http://www.age.mg.gov.br/images/ stories/downloads/advogado/Pareceres2017/parecer-15.877.pdf>. Acesso em: 23 dez. 2017.

NAVES, Bruno Torquato de Oliveira; REIS, Émilien Vilas Boas. Bioética ambiental - premissas para o diálogo entre a Ética, a Bioética, o Biodireito e o Direito Ambiental. 1. ed. Rio de Janeiro: Lumen Juris, 2016. 